\title{
FANTASIA E IDEOLOGIA: O “LIXO” QUE INGERIMOS DIARIAMENTE
}

\author{
Ana Carolina Nunes Silva (UFRN) ${ }^{1}$ \\ Imaculada Kangussu (UFOP)
}

Resumo: O presente artigo visa apresentar o conceito de "fantasia ideológica" no pensamento de Slavoj Žižek. Por meio do qual, o filósofo esloveno mostra a inevitabilidade da ideologia em nossas vidas, isto é, não há como sair da esfera ideológica, qualquer tentativa de desvencilhamento ideológico, nada mais é que uma ideologia. Na perspectiva do filósofo, a ideologia, mais do que ser algo imposto para nós, mas nossa relação mediada com o mundo, na medida em que opera segundo a lógica da "fantasia". Žižek insiste na dimensão ideológica da fantasia e na dimensão fantasiosa da ideologia como forma de crítica, já que a ideologia operaria de acordo com as mesmas formas de ocultamento ou inversão da realidade, assim como a fantasia. De acordo com Lacan, pilar da filosofia de Žižek, a fantasia atua como uma forma de obnubilar as falhas de consistência da realidade simbólica. Para o filósofo esloveno, a realidade tem a estrutura de uma ficção, pois é construída a partir da simbolização limitada, isto é, a realidade é uma espécie de interpretação de um determinado ponto do Real. Sendo assim, o Real irrompe em momentos que frequentemente consideramos "ficcionais" ou "fantasiosos". Žižek alega que, necessitamos direcionar a crítica à realidade efetiva para poder da fantasia, pois como afirmou Lacan, não há outra entrada do sujeito no real senão a fantasia. Isso significa que nenhuma ideologia ou nenhuma sociedade está fechada em si mesma: podemos construir e descontruir fantasias. A articulação entre ideologia e fantasia surge como uma forma de renovação da crítica na democracia liberal, momento em que se declarou o "fim das ideologias" e do advento de uma racionalidade cínica.

Palavras-chaves: Žižek, crítica, Lacan, fantasia ideológica.

Abstract: The present paper aims to present the concept of "ideological fantasy" in Slavoj Žižek's thinking. Through this concept the Slovenian philosopher shows the inevitability of ideology in our lives, that is, there's no way out of the ideological

\footnotetext{
${ }^{1}$ Doutoranda do Programa de Pós-graduação da Universidade Federal do Rio Grande do Norte (UFRN), bolsista CAPES. E-mail: lacarolitanunes@ gmail.com

2 Imaculada Maria Guimarães Kangussu fez mestrado e doutorado em Filosofia, na Faculdade de Filosofia e Ciências Humanas da Universidade Federal de Minas Gerais (UFMG), e pós-doutorado na School of Arts and Science da New York University (NYU), como bolsista da CAPES. Dedica-se ao estudo de estética, filosofia da arte e teorias críticas. Leciona no Instituto de Filosofia, Artes e Cultura da Universidade Federal de Ouro Preto (UFOP), escreve ensaios, e organiza publicações, entre elas Kátharsis (Belo Horizonte: Ed. C/Arte, 2002), Theoria Aesthetica (Porto Alegre: Ed. Escrita, 2005), Dimensão estética (Belo Horizonte: Ed. ABRE, 2008), O cômico e o trágico (Ed. 7letras, 2008, Rio de Janeiro), Estéticas do deslocamento (Belo Horizonte: Ed.ABRE, 2008), Fantasia \& crítica (Belo Horizonte Ed.ABRE, 2012). É autora de Sobre Eros (Belo Horizonte: Ed. Scriptum, 2007) e de Leis da liberdade (São Paulo: Ed. Loyola, 2008). É editora da revista ARTEFILOSOFIA (www.raf.ufop.br) e sua pesquisa atual tem como tema as articulações entre Fantasia e realidade.
} 
sphere. Any attempt to get rid of ideology is but another ideology. In the philosopher's perspective ideology is more than something imposed to us. It is also the fruit of our mediated relations with the world, because it acts according to the logic of "fantasy". Žižek insists on the ideological dimension of fantasy, as well as on the fanciful dimension of ideology as a way of criticism, for ideology works according to the ways of either covering or inverting reality, as fantasy does. According to Lacan, pillar of Žižek's philosophy, fantasy acts as a way to hide consistency faults of symbolic reality. Reality is structured like fiction, because it is built from a limited symbolization, that is, reality is a kind of interpretation of a specific point of the Real. So, the Real breaks through in moments we often consider "fictional or fanciful". Žižek claims that it is necessary to direct effective reality criticism to the power of fantasy because, as Lacan affirms, only through fantasy can one enter the Real. This means that no ideology or society is absolutely closed in itself, for we can do and undo fantasies. The articulation between ideology and fantasy appears as a form of renewing the criticism in liberal democracy, moment at which the end of ideology was declared and cynical rationality took place. Keywords: Žižek, criticism, Lacan, ideological fantasy.

\section{INTRODUÇÃO}

Para entendermos melhor o título deste trabalho, a saber, a relação entre fantasia, ideologia e "lixo", atentemos ao seguinte comentário de Slavoj Žižek sobre o funcionamento da ideologia, no início de seu documentário O Guia Perverso da Ideologia (2012) a partir do filme Eles Vivem (1988), de John Carpenter. O filósofo analisa uma cena em que o personagem John Nada obriga seu amigo a colocar certos óculos que funcionam como uma espécie de "crítica da ideologia": quem quer colocasse esses óculos tornar-se-ia capaz de ver a realidade tal qual "realmente é", sob o véu de ilusões das aparências. "Ou você coloca esses óculos ou comerá na lata de lixo", diz John ao amigo. Žižek comenta:

Eu estou o tempo todo comendo na lata de lixo. Esta lata de lixo se chama ideologia. A força material da ideologia não me deixa ver o que estou realmente comendo. Não é só a nossa realidade que nos escraviza. A tragédia de nossa condição humana é que quando estamos dentro da ideologia, é quando pensamos que escapamos dela para os nossos sonhos. É nesse ponto que estamos realmente dentro da ideologia ( $O$ Guia Perverso da Ideologia, 2012, p. 01).

A partir dessa relação entre ideologia e fantasia, Žižek mostra-nos certa "inevitabilidade" da ideologia em nossas vidas. Esse é o paradoxo que qualquer crítica à

\begin{tabular}{|l|l|l|l|l|}
\hline Q & Dovista \\
\hline
\end{tabular}


ideologia precisa enfrentar. Logo adiante, seguindo no comentário do filme, o filósofo salienta que "a ideologia não é simplesmente algo imposto a nós. A ideologia é nossa relação espontânea com o mundo social, é como percebemos seu significado etc. etc. Nós gostamos da nossa ideologia. Sair dela é doloroso" (O Guia Perverso da Ideologia, 2012). O referencial teórico crítico mobilizado por Zizek é uma leitura marxistapsicanalítica da contemporaneidade. Nesse sentido, o filósofo busca pensar a causa das ideologias, que se encontra no elemento excedente, no "a-mais" que sustenta a fantasia ideológica: uma ideologia que nos apresenta como uma falsa relação entre realidade e saber. Para deixar claro esse funcionamento, deve-se compreender o papel da ideologia e da fantasia na filosofia zizekiana, desse modo, ventilaremos alguns aspectos de tal conceito que ainda permanece em aberto, não encontrou um tipo de sistematização no pensamento de Žižek.

Conduzir a discussão do marxismo para psicanálise lacaniana como peças complementares pode parecer obsoleto, visto que o filósofo enxerga tal relação entre esses saberes através das lentes da filosofia hegeliana, isto é, ele recoloca ambas teorias em um novo território filosófico. Porém, aqui será destacada a importância de tal conceito como uma grande contribuição zizekiana para a teoria da ideologia, visto que o conceito de fantasia ideológica surge como uma forma de renovação à teoria da ideologia marxista e da crítica, numa época em que se declara o "fim das ideologias" e o advento de uma razão cínica.

Tal tarefa de Žižek partiu na companhia das reflexões do filósofo Peter Sloterdijk em sua obra Crítica da Razão Cínica (1983). Polêmica obra onde o filósofo trata o conceito de "cinismo", pela primeira vez, como uma estrutura de racionalidade. A razão cínica é a inversão daquela concepção marxista tradicional de falsa consciência (Eles não sabem o que fazem) incapaz de compreender a totalidade das estruturas causais que suportam as reproduções sociais. Ou seja, razão cínica é a falsa consciência esclarecida: "Eles sabem, mas o fazem". Na perspectiva de Sloterdijk, a difusão do cinismo e sua transformação em mentalidade coletiva, as bases morais tradicionais da crítica à ideologia entraram em colapso. E quanto mais uma sociedade se viu sem alternativas, sem expectativas de mudanças sociais através da crítica que pudesse proporcionar a desalienação - mais ela se orientou por uma racionalidade cínica.

Pois bem, a partir dessa perspectiva, Žižek afirma que só não vivemos em uma era "pós-ideológica" porquanto o "cínico" saiba da mentira sobre as preposições

\begin{tabular}{|c|c|c|c|c|}
\hline Rovista Dialectus & Ano 3 & n. 9 & Setembro - Dezembro 2016 & p. $6-16$ \\
\hline
\end{tabular}


ideológicas, ele desconhece, no entanto, a "fantasia" que estrutura sua realidade social. Isso significa que, os sujeitos podem não acreditar, mas as práticas e os objetos acreditam por ele. A fantasia ideológica é uma crença fundamental que regula nossa realidade social.

\section{O CARÁTER FANTASMAGÓRICO DA IDEOLOGIA}

$\mathrm{Na}$ tradição marxista, o conceito de ideologia encontra-se quase sempre ligado à "falsa consciência", no domínio das relações reificadas que constituem uma aparência socialmente necessária e uma "alienação" incapaz de compreender a totalidade das estruturas causais que suportam as reproduções sociais. Ou seja, a ideologia obnubilaria às condições reais que guiam a vida social, pois é um aparato importante da constituição do poder político, econômico e cultural da classe dominante: "Eles não o sabem, mas o fazem" (MARX, 1996, p. 200). Na visão marxista tradicional, a "crítica", entendida como uma "leitura sintomal" da realidade social, poderia instaurar um regime de relações "não-reificadas", trazendo à cena os mecanismos ideológicos que produzem o sentido para a realidade em curso.

O filósofo coordena uma leitura sintomal do "fetichismo da mercadoria" com uma interpretação lacaniana. Žižek sublinha que a "forma-mercadoria" é uma espécie de a priori do conhecimento, e com isso, no ato de troca, os indivíduos procedem "como se" a mercadoria não estivesse sujeita a trocas físicas e materiais, como se ela estivesse excluída do ciclo natural da degradação, embora, no nível da "consciência", eles "saibam muito bem" que isso não acontece:

Sei muito bem, mas, ainda assim... As explicações correntes dessa fórmula ("sei que minha mãe não tem falo, mas, ainda assim... [acredito que ela o tem]", "Sei que os judeus são agentes como nós, mas, ainda assim [há qualquer coisa neles]".) devemos sem dúvida acrescentar também a variante do dinheiro: "sei que o dinheiro é um objeto material como os outros, mas, ainda assim..." [é como se ele fosse feito de uma substância especial, sobre a qual o tempo não tem nenhum poder] (ŽIŽEK, 1999, p.330).

\begin{tabular}{|c|c|c|c|c|}
\hline Qevista Dialectus & Ano 3 & n. 9 & Setembro - Dezembro 2016 & p. $6-16$ \\
\hline
\end{tabular}


Ora, o que há de fetichismo no fetichismo da mercadoria? O que fazem exatamente os sujeitos quando produzem? Marx mostra que, no interior da economia das sociedades capitalistas industriais, os sujeitos, ao produzirem mercadorias, projetariam isso no sentido de não poderem mais se reconhecer naquilo que eles mesmos fazem e produzem. No ato do consumo, são fetichizados não apenas os objetos, mas a própria ação de adquirir a mercadoria, pois suas características sensíveis e físicas são apagadas em prol de um determinado valor que deve ser encarnado. É esse processo "fantasmagórico" que permite desconsiderar-se a materialidade de todo objeto singular e de todo o sensível em geral.

Ao contrário do "modo sintomal", a ideologia atua de modo cada vez mais "fetichista". Na perspectiva marxista, o método sintomal da crítica à ideologia poderia instaurar uma universalidade sem seu sintoma. Nessa operação, a mentira ideológica que estrutura nossa percepção da realidade é ameaçada por sintomas como "retornos do recalcado"; em outras palavras, como rasgos na superfície da mentira ideológica. Enquanto, por outro lado, o fetiche é a personificação da mentira, é a "falsa aparência" que permite sustentar-se a verdade insuportável.

Žižek nos dá um bom exemplo para entendermos o papel do "fetiche" neste caso:

Vejamos o caso da morte de um ente querido: o caso do sintoma, "reprimindo" essa morte, tento não pensar nela, mas o trauma reprimido retorna no sintoma; no caso do fetiche, ao contrário, aceito inteira e "racionalmente" essa morte, mas, ainda assim, agarro-me ao fetiche, a alguma característica que personifica, para mim, a desautorização da morte. Nesse sentido, o fetiche pode ter o papel muito construtivo de permitir que lidemos com a dura realidade: os fetichistas não são sonhadores perdidos em seu mundo particular, são totalmente "realistas", capazes de aceitar o modo como as coisas são porque, ao se agarrar ao fetiche, conseguem mitigar o impacto total da realidade (ŽIŽEK, 2009, p.62).

A partir dessa perspectiva, podemos entender o clássico exemplo de Žižek sobre a ideologia "fascista-populista", cuja concepção política envolve uma falsa identificação dos antagonismos presentes em nossa realidade social e, portanto, fetichiza este obstáculo na luta contra os judeus. Ou seja, análogo a tal ideia, o ódio popular da exploração oriunda das relações capitalistas é deslocada para uma "conspiração

\begin{tabular}{|l|l|l|l|l|}
\hline Q & Dovista \\
\hline
\end{tabular}



Ana Carolina Nunes Silva (UFRN) / Imaculada Kangussu (UFOP)

judaica", pois quando o fascista proclama "os judeus são a causa de nosso sofrimento", o que está por trás desse discurso é "o capital é a causa de nosso sofrimento". Nesse ponto, Žižek alerta ainda para o fato de que, nessa mistificação, necessitamos da dupla "sintoma e fetiche": o judeu é o fetiche dos antissemitas, e é ao que eles se agarram em vez de confrontar a luta de classe. No procedimento sintomal e no fetiche, o papel estrutural é o mesmo: se esse elemento excepcional for perturbado, todo o sistema se desintegra.

Em outras palavras, “uma ideologia está realmente 'nos prendendo' apenas quando não sentimos qualquer oposição entre ela e a realidade - quer dizer, quando a ideologia tem sucesso em determinar o modo de nossa experiência cotidiana da realidade mesma" (ŽIŽEK, 1989, p.49). Ao contrário, quando, e se, a experiência cotidiana "real" entra em choque com o projeto ideológico isso indica que a ideologia não produziu seus esperados efeitos. Desse ponto de vista, vale examinar as peripécias realizadas pelas operações simbólicas a fim de produzir a suprema fantasia ideológica de anular a distância entre o real e o modo de apreensão deste por ela proposto, como se este último fosse articulado apenas por fatos e não também por quimeras. Segundo o filósofo, tanto a suposição de que a materialidade da experiência cotidiana pode oferecer resistência por constituir um real que a ideologia não consegue abolir sem deixar restos, quanto "as tentativas de fazer valer a riqueza do 'concreto' em oposição ao caráter abstrato das determinações simbólicas simplesmente passam ao largo do mecanismo fundamental da simbolização, o do "basteamento"” (ŽIŽEK, 1991, 1996).

O êxito do mecanismo de basteamento ocorre quando um elemento, que rejeita e desmente a ideologia, passa a funcionar ao contrário, isto é, quando um elemento que desmente a ideologia passa a funcionar como prova de sua validade e a fornecer à tese que refuta uma redobrada confirmação. O "basteamento" consiste, portanto, na operação de inverter a falta presente na ideologia - que aparece no embate desta com o cotidiano - em seu oposto, em um signo de sua supremacia sobre a realidade. Como exemplo desse movimento de inversão, Žižek apresenta o modo de lidar com a distância existente entre a imagem ideológica do judeu disseminada por anti-semitas - como ser demoníaco causador da decomposição das estruturas sociais - e a possível experiência concreta de um amável convívio cotidiano com um gentil vizinho judeu. Neste caso, a operação de "basteamento", ao invés de perceber a distância existente entre a imagem ideológica negativa e a experiência cotidiana positiva como um obstáculo e um limite à

\begin{tabular}{|l|l|l|l|l|}
\hline Q & Dovista \\
\hline
\end{tabular}


ideologia antissemita, consiste em incluí-la de antemão no funcionamento da ideologia, i.e, "a discordância funciona como uma prova suplementar, ainda mais eficaz, da depravação judaica - 'tomem cuidado com os judeus: é difícil identificá-los porque eles tem o jeito das pessoas comuns, comportam-se como pessoas amáveis para dissimular sua natureza corrupta!"” (ŽIŽEK,1991, p. 196).

\section{A FANTASIA IDEOLÓGICA}

A partir de tal análise, aterrissamos no território do conceito de fantasia. No âmbito da filosofia o conceito de fantasia recebeu diversos sentidos. O conceito de fantasia pode ser melhor entendido a partir do papel atribuído por Kant a imaginação no processo de conhecimento. No esquema kantiano, a imaginação é a faculdade que realiza o intercâmbio entre sensibilidade e entendimento, isto é, a que liga o fenômeno ao conceito. Na Crítica da Razão Pura (1783), Kant elabora o esquematismo transcendental para realizar o processo de conhecer, onde a imaginação aparece como uma espécie de dimensão intermediária entre o conteúdo empírico (os objetos empíricos) e a rede de categorias transcendentais: é o nome do mecanismo pelo qual os objetos empíricos são incluídos na rede de categorias transcendentais que determinam a maneira como percebemos e concebemos nossa realidade. Por meio dessa analogia com o esquematismo kantiano, funcionando como dimensão intermediária entre o sensível e o inteligível, esta instância lida com o imaginário social e cria a moldura a partir da qual é formatada uma determinada visão da realidade. Além de ser impossível o acesso direto à "coisa-em-si", e apenas os fenômenos dados à sensibilidade poderem ser conhecidos, para que o conhecimento aconteça tais fenômenos precisam ser ligados às categorias do entendimento. E é esta a função da imaginação. Quer dizer, entre o fenômeno percebido e o conceito que lhe é atribuído há o trabalho da imaginação. O conhecimento nunca é direto e objetivo. É por esta razão que, assim como no esquematismo se conhece através da imaginação, pode-se perceber o papel constitutivo das fantasias, ou ideologias, na constituição de qualquer visão de mundo.

Nesse sentido, em Lacan temos a "coisa-em-si” como Real, o que é impossível de ser alcançado imediatamente, pois há uma rede simbólica que configura nossa realidade. Em Žižek, a fantasia aparece como uma dimensão crítica, pois é um modo de o sujeito lidar como esse "inefável”, irrepresentável, isto é, com a impossibilidade de configuração integral da rede simbólica. Nas palavras do filósofo, "o que

\begin{tabular}{|l|l|l|l|l|}
\hline Qevista Dialectus & Ano 3 & n. 9 & Setembro - Dezembro 2016 & p. 6 - 16 \\
\hline
\end{tabular}


experimentamos como "realidade" é estruturado pela fantasia, e se a fantasia serve como crivo que nos protege, impedindo que sejamos diretamente esmagados pelo real cru, então a própria realidade pode funcionar como uma fuga de um encontro com o real" (ŽIŽEK, 2010, p.73).

Em suma, na perspectiva lacaniana, a fantasia é fundamentalmente uma criação indispensável. Não uma mentira no sentido de ser só "mera" fantasia, mas uma mentira no sentido de que a fantasia encobre uma certa falha da consistência simbólica, ela impede nosso encontro com o deserto do real (ŽIŽEK, 2005). Žižek insiste na existência de uma "fantasia social" que também pode ser conhecida com o nome de "ideologia" e que determina o valor e a significação da realidade socialmente compartilhada. A fantasia social funciona como ilusão inconsciente e, porque para funcionar precisa permanecer velada, implica a consideração de que realidade criada através de percepções formatadas por ela, pela fantasia social, é de fato a única e verdadeira possibilidade de uma realidade efetiva. A fantasia é a cena imaginária que oferece as coordenadas e o roteiro do desejo. Conforme o filósofo, a fantasia ensina-nos a desejar: "a causa do desejo é o traço em razão do qual desejamos o objeto. Trata-se de algum detalhe ou tique do qual em geral somos inconscientes" (ŽIŽEK, 2010, p. 85).

A fantasia ideológica depende da constituição da esfera trans-ideológica desse objeto sublime para nossa ordem sociossimbólica, e para captá-la é preciso estar atenta a esses "excessos" ideológicos. Ainda em seu documentário O Guia Perverso da Ideologia (2012), Žižek alega que esse elemento "a-mais" é aquele capaz de transformar uma Coca-Cola quente e intragável em objeto sublime. Por este motivo, não podemos superar a fascinação produzida por ele sem entendermos o papel desse "a-mais", o excesso, em nossas vidas. Quando desvendamos esse elemento ideológico, ele cai e se torna um mero dejeto.

E, mais ainda, à impossibilidade de descartamos toda ideologia, ao papel constitutivo da ideologia na construção do assim chamado "mundo real”. Žižek salienta que a forma mais aguda de autoengano não está em deixar-se enredar pela ideologia e esquecer sua base material, e sim em pretender deixá-la de lado a visando tratar imediatamente da realidade, composta de "pessoas reais com preocupações reais" (ŽIŽEK, 2011a, p. 303). Nesta perspectiva, mistificação é não considerar a fantasia como parte necessária da realidade simbólica, que é a única realidade a que temos acesso. Mistificação seria desconsiderar a real necessidade das fantasias.

\begin{tabular}{|c|c|c|c|c|}
\hline Rovista Dialectus & Ano 3 & n. 9 & Setembro - Dezembro 2016 & p. $6-16$ \\
\hline
\end{tabular}


Grosso modo, quando nossa visão sobre a realidade se embaça ou quando as coisas estão turvas e somos incapazes de resolver os problemas definitivamente, a fantasia atua nos dando uma solução "fácil” (“morte aos judeus”). Para Žižek, é desse modo que funciona a ideologia democrática liberal. Um exemplo desse fato, que vale a pena ser sublinhado, é o atentado ao jornal Charlie Hebdo, ocorrido em Paris em 7 de janeiro de 2015, após a publicação da edição que gerou bastante polêmica por ofender o mundo islâmico. O episódio ocasionou grandes manifestações com a adoção da posição "je suis Charlie" e tornou-se marca comum, em todo mundo, de expressão de solidariedade contra o ataque "terrorista". Porém, o "je suis Charlie" tornou-se a expressão da subjetividade majoritária na França que tem um apreço pelo colonialismo e pelo sistema neoliberal do capitalismo. A comoção sobre o atentado ao Charlie Hebdo é uma forma de deslocar os problemas do neocolonialismo e a justificação da atuação cada vez mais violenta da polícia contra imigrantes e refugiados. Ou seja, o "terrorismo" tornou-se a marca para a ascensão de uma política cada vez mais conservadora, autoritária deixando os "reais" problemas de lado.

\section{CONCLUSÃO}

Haveria uma forma de comer fora da lata de lixo? O filósofo acredita que podemos mudar radicalmente a ordem das aparências e o que gera tal mudança está na compreensão de que sempre há uma abertura para o Real. Isso é o que nos impediria de cair no niilismo, no cinismo de pensar que "as coisas estão dadas e nada pode ser feito".

Para finalizar direcionaremos o debate para um fato interessante, que podemos associar à fantasia ideológica. Recentemente, o filósofo Christian Dunker publicou um artigo intitulado "Por que ensinar mais Žižek em nossas escolas? ”, , apontando a urgência do ensino da filosofia zizekiana, nas escolas do país, como ferramenta de combate a um "espírito" conservador que permeia o âmbito da educação brasileira. Na acepção de Dunker, "o filósofo esloveno critica marxistas, feministas, ecologistas e multiculturalistas, mas defende explicitamente a liberdade e a Constituição.

\footnotetext{
3 Artigo publicado na Revista Brasileiros no dia 18/08/16: http://brasileiros.com.br/2016/08/por-queensinar-mais-zizek-em-nossas-escolas/
}

\begin{tabular}{|c|c|c|}
\hline Rovista Dialectus & Ano 3 & n. \\
\hline
\end{tabular}



Ana Carolina Nunes Silva (UFRN) / Imaculada Kangussu (UFOP)

Esse "espírito bastardo" do conservadorismo já identificamos, quando o tema da redação do "Exame Nacional do Ensino Médio" (Enem), de 2015, foi o feminismo, baseado na célebre frase da filósofa francesa Simone de Beauvoir em sua obra $O$ Segundo Sexo (1949): "Não se nasce mulher, torna-se mulher". Abordar o feminismo causou uma grande polêmica por parte de muitos políticos conservadores que afirmaram que a questão do exame do ensino médio é uma tentativa de incutir nas "puras mentes" dos jovens "culturas estranhas aos nossos costumes e tradições".

Conjuntamente a este episódio, surge o "Programa escola sem partido"4 (lei número 867/2015), que é um projeto de lei que pressupõe uma certa neutralidade no ensino, isto é, contra “ a doutrinação” política e ideológica em sala de aula. Felizmente não foi aprovado, mas ainda é um fantasma que até agora ronda a sociedade brasileira.

Primeiramente, o problema reside no fato que a maioria dos partidários de tal lei afirma que escola "sem partido" é o oposto da escola "com partido", mas não é bem assim. Como vimos em Žižek, essa exigência de neutralidade nada mais é que uma outra forma de ideologia. Dizer que não existe imparcialidade não significa que somos desonestos e sim admitir que não há como considerar todos os pontos de vistas ao mesmo tempo e a todo momento. E que nossos saberes têm efeitos na realidade e moldam a sociedade de diferentes maneiras. Ou seja, quem não assume a neutralidade é ideológico, mas o que seria essa tal neutralidade? Se um professor priorizar ensinar mais a história da América Latina ou outros temas bastante relevantes em nossa sociedade como o racismo e o feminismo, por exemplo, será ideológico. Porém, se o educador der mais importância ao ensino sobre os móbiles da Revolução Francesa, será neutro, posto que não estará "corrompendo os jovens com culturas estranhas aos costumes e tradições" já impostas pela cultura hegemônica.

Casos como estes nos mostram como as reflexões de Žižek contribuem para ressuscitar o debate no âmbito das ideologias como forma de crítica à democracia liberal e sua estrutura cínica, além de nos fornecer uma ferramenta de combate às posturas anticríticas, anti-intelectuais que permeia nossa atual conjuntura.

\section{Referências Bibliográficas:}

ŽIŽEK, S. O mais sublime dos histéricos. Hegel com Lacan. Trad. Vera Ribeiro. Rio de Janeiro: Zahar, 1991.

\footnotetext{
${ }^{4}$ Projeto de lei do deputado Izalci (PSDB/DF) apresentado em 23/03/2015
}

\begin{tabular}{|l|l|l|l|l|}
\hline Qenista Dialectus & Ano 3 & n. 9 & Setembro - Dezembro 2016 & p. 6 - 16 \\
\hline
\end{tabular}


. (Org.). Um mapa da ideologia. Tradução de Vera Ribeiro. Rio de Janeiro:

Contraponto, 1996.

. Bem-vindo ao Deserto do Real. Tradução Paulo César Castanheira. São Paulo: Boitempo, 2005. 2009.

. \& FIENNES, S. The Pervert's Guide to Cinema. Direção: Sophie Fiennes, . Como Ler Lacan? Tradução Maria Luiza X. de A. Borges. Rio de Janeiro: Jorge Zahar, 2010.

Em defesa das causas perdidas. Tradução Beatriz Medina. São Paulo: Boitempo, 2011a.

.The Pervert's Guide to Ideology. Direção: Sophie Fiennes, 2012.

KANT. Crítica da Razão Pura. Tradução Tradução de Manuela Pinto Santos e Alexandre Fradique Morujao. Lisboa: Calouste Gulbenkian, 1994.

MARX, K. O Capital: crítica da economia política. Tradução Régis Barbosa e Flávio R. Kothe. São Paulo: Nova Cultural, 1996. (Livro 1, vol. I)

SLOTERDIJK, P. Crítica da Razão Cínica. Tradução Marco Casanova. Rio de Janeiro: Estação liberdade, 2013. 